Available online at GSC Online Press Directory

GSC Biological and Pharmaceutical Sciences

e-ISSN: 2581-3250, CODEN (USA): GBPSC2

Journal homepage: https://www.gsconlinepress.com/journals/gscbps

(RESEARCH ARTICLE)

\title{
The positivity rate of Epstein-Barr virus anti-viral capsid antigen IgG among children with infectious mononucleosis in Diyala-Iraq
}

\author{
Mohammad Kassem Saleh *, Abdulrazak Shafiq Hasan and Nadhim Ghazal Noaman \\ College of Medicine-Diyala University, Baqubah, Iraq.
}

Publication history: Received on 15 November 2020; revised on 27 October 2020; accepted on 02 December 2020

Article DOI: https://doi.org/10.30574/gscbps.2020.13.3.0392

\begin{abstract}
Background: Epstein-Barr virus (EBV) is a double-stranded linear DNA human herpesvirus that is transmitted primarily through saliva during childhood. Although the majority of primary EBV infections are clinically asymptomatic, clinical cases are presented as infectious mononucleosis (IMN) syndrome.
\end{abstract}

Objectives: This study was conducted to explore the rate of EBV anti-VCA IgG among children who were clinically suspected as having IMN in Diyala province.

Subjects and methods: This is a cross sectional study that was carried out during 2018 in Diyala province- Iraq. A total of 370 blood samples were collected from 190 children under 15 years of age who were clinically suspected as having IMN, and 180 apparently healthy children as controls. The anti EBV VCA IgG antibodies were detected in serum using the VCA IgG ELISA kit (from Dia.Pro Diagnostic Bioprobes srl - Italy). Statistical analysis was carried out using the SPSSversion 25. A statistical significance was considered whenever the P value was $\leq 0.05$.

Results: The results showed that the IgG positivity rate among suspected IMN patients was insignificantly higher in the age group $10-14$ years old children $(80.8 \%, \mathrm{P}=0.364)$. In control subjects the highest positivity rate was in the age group of 1-4 years with a statistically significant difference $(79.5 \%, \mathrm{P}=0.002)$. In suspected IMN patients, the age group of 10-14 years had the highest mean concentration \pm SD of anti-VCA IgG (44.018 \pm 38.644 arbitrary units per milliliter $(\mathrm{arbU} / \mathrm{ml}))$, while in controls, the highest value $(38.018 \pm 34.908 \mathrm{arbU} / \mathrm{ml})$ was in the age group of $1-4$ years, with insignificant difference in either group $(\mathrm{P}=0.257$ and 0.072 , respectively). The results also showed that in both suspected IMN patients and control subjects, females showed higher IgG positivity rate (70.6\%, and 75.5\%) compared to males (64.8\%, and 65.1\%) with insignificant difference in both groups ( $\mathrm{P}=0.392$ and 0.126 , respectively). Similarly, the IgG mean concentration \pm SD was insignificantly higher in females in both suspected IMN patients and control subjects $(\mathrm{P}=0.447$ and 0.256 , respectively). $21(87.5 \%)$ IgM positive suspected IMN patients were also IgG positive with a statistically significant association $(\mathrm{P}=0.028)$.

Conclusion: The positivity rate of anti-EBV VCA IgG among apparently healthy subjects in Diyala province was 70.6\%, and the rate increases with age, with slight association with clinical suspicion of infectious mononucleosis.

Keywords: Epstein-Barr virus; Infectious mononucleosis; Anti-VCA IgG

\section{Introduction}

Epstein-Barr virus (EBV) is a DNA lymphotropic herpesvirus and the causative agent of infectious mononucleosis. EBV is highly prevalent since it affects more than $90 \%$ of individuals worldwide and has been linked to several malignancies [1]. Over $90 \%$ of the population are seropositive for EBV worldwide. Most children are infected by the age of 2 years in

\footnotetext{
${ }^{*}$ Corresponding author: Mohammad Kassem Saleh

College of Medicine-Diyala University.
}

Copyright (@ 2020 Author(s) retain the copyright of this article. This article is published under the terms of the Creative Commons Attribution Liscense 4.0. 
developing countries, while in developed countries EBV infection occurs more often in late childhood and adolescence [2]. The majority of primary EBV infections in infants and young children are clinically silent. In older patients, it is accompanied by symptoms of infectious mononucleosis (IMN) in about $50 \%$ of cases [3]. IMN is a clinical syndrome characterized by pharyngitis, cervical lymphadenopathy, fever, and lymphocytosis, and is most often caused by EBV [4]. In addition to IMN, EBV also causes other clinical syndromes and is associated with various lymphoid and non-lymphoid malignancies [5].

One of the commonly used diagnostic techniques is enzyme linked immunosorbent assay (ELISA). The presence of antiVCA IgM antibodies indicates current infection while anti-VCA IgG antibody is a marker of past infection and indicates immunity [5]. In China, among children 22 days to 14 years of age with suspected EBV infection, the positivity rate for EBV infection was 14.3\% [6]. Similar studies had yielded comparable results [7-9].

Chabay and Preciado (2013) reported that the anti-VCA IgG prevalence among children less than 15 years of age in Argentina was 72\% [10]. Similar results were also found in most previous studies [8, 11, 12]. Epstein-Barr virus infection is very common in the United States since more than $90 \%$ of adults are antibody positive by the age of 35 years. However, the EBV antibodies prevalence among children is lower, ranging from $20 \%$ to $80 \%$ depending on age and geographic location [13]. EBV seroprevalence in pregnant women in Finland has remained the same in the last 20 years [14]. In Scotland, among university-aged population, 75\% were seropositive and almost half of the remaining seronegative students experienced seroconversion during their time at university [15]. In China, children under 4 years of age are highly susceptible to infection and children between 6 months and 1 year of age are the high-risk group for EBV infection. Therefore, vaccination against EBV was recommended to reduce the burden of EBV infection in future [16].

\section{Subjects, material and methods}

This is a cross sectional study that was carried out during 2018 in Diyala province- Iraq, for the serological detection of anti-viral capsid antigen IgG antibodies against Epstein-Barr virus in clinically suspected cases of IMN as well as apparently healthy children less than 15 years of age.

A total of 370 blood samples were collected as follows; 190 samples from children under 15 years of age who were clinically suspected as having IMN, and 180 samples from normal apparently healthy children (under 15 years of age). A questionnaire form was pre-constructed for this objective including socio-demographic information. The anti EBV VCA IgG antibodies were detected in serum using the VCA IgG ELISA kit (from Dia.Pro Diagnostic Bioprobes srl - Italy). Statistical analysis of data was carried out using the SPSS-25 (Statistical Packages for Social Sciences- version 25). Data were presented in simple measures of frequency, percentage, mean, standard deviation, and range. The significance of difference in means were tested using Students-t-test. The significance of difference of percentages were tested using Pearson Chi-square test ( $\chi 2$-test). Statistical significance was considered whenever the P value was equal to or less than 0.05 .

\section{Results}

Table (1) shows that both suspected IMN patients and apparently healthy subjects had approximately similar positivity rates for anti-VCA IgG (67.9\% and 70.6\%, respectively). As a result, there is no statistically significant association between the two groups $(\mathrm{P}=0.580)$.

Table 1 Association of anti-VCA IgG status with clinical suspicion of IMN.

\begin{tabular}{|l|l|l|l|l|}
\hline \multirow{2}{*}{ Anti-VCA IgG status } & \multicolumn{2}{|l|}{ Suspected IMN patients } & \multicolumn{2}{l|}{ Apparently healthy } \\
\cline { 2 - 5 } & No. & \% & No. & \% \\
\hline Positive & 129 & 67.9 & 127 & 70.6 \\
\hline Negative & 61 & 32.1 & 53 & 29.4 \\
\hline P value & 0.580 & & & \\
\hline
\end{tabular}

Table (2) demonstrates that IgG positivity rate among suspected IMN patients increases with age (from $60 \%$ among those less than 1 year of age, to $80.8 \%$ in those $10-14$ years old), however the difference was statistically insignificant 
$(\mathrm{P}=0.364)$. On the other hand, control subjects showed the highest positivity rate in the age group of $1-4$ years $(79.5 \%)$ and the lowest in those less than 1 year of age (39.1\%) concluding that there is a statistically significant association between IgG status and age in control subjects $(\mathrm{P}=0.002)$

Table 2 Association of anti-VCA IgG status with age.

\begin{tabular}{|c|c|c|c|c|c|c|c|c|}
\hline \multirow{4}{*}{ Age (years) } & \multicolumn{8}{|c|}{ Anti-VCA IgG status } \\
\hline & \multicolumn{4}{|c|}{ Suspected IMN patients } & \multicolumn{4}{|c|}{ Control } \\
\hline & \multicolumn{2}{|c|}{ Positive } & \multicolumn{2}{|c|}{ Negative } & \multicolumn{2}{|c|}{ Positive } & \multicolumn{2}{|c|}{ Negative } \\
\hline & No. & $\%$ & No. & $\%$ & No. & $\%$ & No. & $\%$ \\
\hline$<1$ & 12 & 60.0 & 8 & 40.0 & 9 & 39.1 & 14 & 60.9 \\
\hline $1-4$ & 56 & 64.4 & 31 & 35.6 & 62 & 79.5 & 16 & 20.5 \\
\hline 5-9 & 40 & 70.2 & 17 & 29.8 & 40 & 74.1 & 14 & 25.9 \\
\hline $10-14$ & 21 & 80.8 & 5 & 19.2 & 16 & 64.0 & 9 & 36.0 \\
\hline$P$ value & \multicolumn{4}{|c|}{0.364} & \multicolumn{4}{|c|}{0.002} \\
\hline
\end{tabular}

Table (3) shows that in suspected IMN patients, the age group of 10-14 years had the highest mean concentration \pm SD of anti-VCA IgG (44.018 \pm 38.644$)$, while in control subjects, the highest value $(38.018 \pm 34.908)$ was in the age group of 1-4 years. The difference was statistically insignificant in either group ( $\mathrm{P}=0.257$ and 0.072 , respectively).

Table 3 Association of anti-VCA IgG concentration with age.

\begin{tabular}{|c|c|c|c|c|}
\hline \multirow{3}{*}{ Age (years) } & \multicolumn{4}{|c|}{ Anti-VCA IgG concentration (arbU/ml) } \\
\hline & \multicolumn{2}{|c|}{ Suspected IMN patients } & \multicolumn{2}{|l|}{ Control } \\
\hline & Mean $\pm S D(\operatorname{arbU} / m l)$ & Range & Mean \pm SD (arbU/ml) & Range \\
\hline$<1$ & $26.210 \pm 35.292$ & $0.278-100$ & $16.831 \pm 32.027$ & $0.139-100$ \\
\hline $1-4$ & $29.985 \pm 32.930$ & $0-100$ & $38.018 \pm 34.908$ & $0.104-100$ \\
\hline $5-9$ & $32.717 \pm 33.853$ & $0-100$ & $30.049 \pm 32.909$ & $0.174-100$ \\
\hline $10-14$ & $44.018 \pm 38.644$ & $0.208-100$ & $31.509 \pm 36.766$ & $0-100$ \\
\hline$P$ value & \multicolumn{2}{|l|}{0.257} & \multicolumn{2}{|l|}{0.072} \\
\hline
\end{tabular}

In both suspected IMN patients and control subjects, females showed higher IgG positivity rate $(70.6 \%$, and $75.5 \%)$ respectively compared to males (64.8\%, and 65.1\%, respectively). Nonetheless, the difference was statistically insignificant in both groups ( $\mathrm{P}=0.392$ and 0.126 , respectively), as shown in table (4).

Table 4 Association of anti-VCA IgG status with gender.

\begin{tabular}{|l|l|l|l|l|l|l|l|l|}
\hline \multirow{3}{*}{ Gender } & \multicolumn{7}{|c|}{ Anti-VCA IgG status } \\
\cline { 2 - 9 } & \multicolumn{3}{|l|}{ Suspected IMN patients } & \multicolumn{2}{|l|}{ Control } \\
\cline { 2 - 9 } & Positive & Negative & \multicolumn{2}{l|}{ Positive } & \multicolumn{2}{l|}{ Negative } \\
\cline { 2 - 9 } & No. & $\%$ & No. & $\mathbf{\%}$ & No. & \% & No. & $\%$ \\
\hline Male & 57 & 64.8 & 31 & 35.2 & 56 & 65.1 & 30 & 34.9 \\
\hline Female & 72 & 70.6 & 30 & 29.4 & 71 & 75.5 & 23 & 24.5 \\
\hline
\end{tabular}




\begin{tabular}{|l|l|l|}
\hline P value & 0.392 & 0.126 \\
\hline
\end{tabular}

Table (5) shows that the IgG mean concentration \pm SD is higher in females in both suspected IMN patients and control subjects (34.094 \pm 34.323 and $34.824 \pm 34.205$, respectively). However, no statistically significant association was found in either group ( $\mathrm{P}=0.447$ and 0.256 , respectively).

Table 5 Association of anti-VCA IgG concentration with gender.

\begin{tabular}{|l|l|l|l|l|}
\hline \multirow{2}{*}{ Gender } & \multicolumn{4}{|c|}{ Anti-VCA IgG concentration (arbU/ml) } \\
\cline { 2 - 5 } & Suspected IMN patients & Control \\
\cline { 2 - 5 } & Mean \pm SD (arbU/ml) & Range & Mean \pm SD (arbU/ml) & Range \\
\hline Male & $30.281 \pm 34.499$ & $0-100$ & $28.946 \pm 35.014$ & $0-100$ \\
\hline Female & $34.094 \pm 34.323$ & $0-100$ & $34.824 \pm 34.205$ & $0.139-100$ \\
\hline P value & 0.447 & 0.256 & \\
\hline
\end{tabular}

\section{Discussion}

It was revealed that the positivity rate of IgG among apparently healthy subjects in this study was 70.6\%, which was not significantly different when compared to the rate among suspected IMN patients $(\mathrm{P}=0.580)$, indicating that there is no association between IgG positivity rate and clinical suspicion of IMN.

These current findings were compatible with the results of most previous studies, concerning the rate among children less than 15 years of age $[8,11,12]$. Moreover, Chabay and Preciado (2013) reported that the anti-VCA IgG prevalence among children less than 15 years of age in Argentina was 72\% [10]. On the other hand, Dowd et al. (2013) and Balfour et al. (2013) reported lower IgG positivity rates among children aged 6-14 years in the United States (59.6\%, and 54.6\%, respectively). These rates would have probably been even less if the age group of less than 6 years was included in these studies. However, when the age group of 15-19 years was taken into account in these studies, the rates increased to $66.7 \%$ and $64.4 \%$ respectively $[17,18]$. The inconsistency between the current study and the aforementioned studies is a reflection of the difference in the peak age of acquiring EBV primary infection in Iraq and the USA.

Results of the present study showed a statistically significant association between age and IgG positivity rate among apparently healthy subjects $(\mathrm{P}=0.002)$ with the highest rate being in the age group of $1-4$ years $(79.5 \%)$ and the lowest in those less than 1 year of age (39.1\%). However, no such significant association was found among suspected IMN patients, but the positivity rate increased with age. When taking the entire study population into account, the positivity rates were indicating an increase in the rate with age.

Similar findings were reported by Huang et al. (2013) in the study conducted in China, in which the patients were classified into five age groups. The IgG seropositivity rate increased among children aged 8-36 months and then plateaued among children aged 36-108 months. For children aged $\geq 9$ years, the positivity rate was $84.2 \%$ [12].

In another study conducted in Taiwan, Chen et al. (2015) stated that children under 1 year of age had similar IgG seropositivity rate as that of children between the ages of 1 and 2 years, however the age-specific seropositivity rate quickly rose in the early life. Among the 2 years old children 52.8\% of them had positive anti-VCA IgG response. The rate further increased to $88.7 \%$ in the age group of 5-7 years. For people aged $14-16$ years, the rate reached $93 \%$. These findings had led to the conclusion that the positivity rate significantly increased with age [11]. Moreover, a similar trend of increasing rate with age was also found in most previous studies $[10,17,18]$.

The overall IgG positivity rate in the current study population was $73 \%$ among females and $65 \%$ among males, with no statistically significant effect of gender on the positivity rate. These findings were reconcilable with many previous studies $[11,18]$. Additionally, Dowd et al. (2013) observed that the IgG positivity rate was $68.9 \%$ among females and $64.2 \%$ among males in the USA [17]. However, Pourahamad et al. (2014) reported that the IgG positivity rate was 87.2\% among males and $82.9 \%$ among females in Iran (the mean age of the study group was 23 years, which is much higher than that of the current study, and hence the overall higher rates of IgG positivity) [19]. In another study in Argentina, the IgG positivity rate among males and females was $72 \%$ and $71 \%$ respectively [10]. These minor inconsistencies in 
results might be due to differences in the overall male to female ratio in the study group of these studies compared to the present one.

\section{Conclusion}

The positivity rate of anti-VCA IgG among apparently healthy subjects in Diyala province was $70.6 \%$, there is no association between IgG positivity rate and clinical suspicion of IMN, the IgG positivity rate increases with age, and the overall IgG positivity rate was $73 \%$ among females and $65 \%$ among males. Similar studies should be performed using molecular techniques to reach more accurate results, in addition to DNA sequencing to investigate the geographical distribution of EBV genotypes of local strains, paving the way for vaccine preparation in the future.

\section{Compliance with ethical standards}

\section{Acknowledgments}

We would like to thank each and every individual who have been a source of support and encouragement and helped us achieve our goal and complete this study successfully.

\section{Disclosure of conflict of interest}

The authors declare that there are no relevant financial or non-financial competing interests to report.

\section{Statement of informed consent}

Informed consent was obtained from all individual participants included in the study.

\section{References}

[1] Smatti MK, Al-Sadeq DW, Ali NH, Pintus G, Abou-Saleh H, Nasrallah GK. Epstein-Barr Virus Epidemiology, Serology, and Genetic Variability of LMP-1 Oncogene Among Healthy Population: An Update. Front. Oncol. 2018; 8(211): 2 .

[2] Ryan KJ, Ray CG, Ahmad N, Drew WL, Lagunoff M, Pottinger P, Reller LB, Sterling CR. Sherris Medical Microbiology, $6^{\text {th }}$ edition. McGraw-Hill Education. 2014.

[3] Kliegman RM, Stanton BF, St Geme JW, Schor NF, Behrman RE. Nelson Textbook of Pediatrics, $20^{\text {th }}$ edition. Elsevier, Inc. 2016.

[4] Ralston SH, Penman ID, Strachan MW, Hobson RP. Davidson's Principles and Practice of Medicine, $23^{\text {rd }}$ edition. Elsevier, Inc. 2018.

[5] Carroll KC, Morse SA, Mietzner T, Miller S. Jawetz, Melnick, \& Adelberg's Medical Microbiology, $27^{\text {th }}$ edition. McGraw-Hill Education. 2016.

[6] Chen Q, Hu Z, Zhang QH. Analysis of Epstein Barr virus infection in 761 hospitalized children. Chin. J. Contemp. Pediatr. 2013; 15(3): 183-6.

[7] Sohn MJ, Cho JM, Moon JS, Ko JS, Yang HR. EBV VCA IgM and cytomegalovirus IgM dual positivity is a false positive finding related to age and hepatic involvement of primary Epstein-Barr virus infection in children. Medicine. 2018; 97(38): e12380.

[8] Fourcade G, Germi R, Guerber F, Lupo J, Baccard M, Seigneurin A, Semenova T, Morand P, Epaulard O. Evolution of EBV seroprevalence and primary infection age in a French hospital and a city laboratory network, 2000-2016. PLoS One. 2017; 12(4): e0175574.

[9] Balfour HH, Odumade OA, Schmeling DO, Mullan BD, Ed JA, Knight JA, et al. Behavioral, virologic, and immunologic factors associated with acquisition and severity of primary Epstein-Barr virus infection in university students. J. Infect. Dis. 2013; 207(1): 80-8.

[10] Chabay PA, Preciado MV. EBV primary infection in childhood and its relation to B-cell lymphoma development: A mini-review from a developing region. Int. J. Cancer. 2013; 133(6): 1286-92.

[11] Chen CY, Huang KYA, Shen JH, Tsao KC, Huang YCA. Large-Scale Seroprevalence of Epstein-Barr Virus in Taiwan. PLoS One. 2015; 10(1): e 0115836. 
[12] Huang Y, Wei C, Zheng K, Zhao D. The impact of serological features in Chinese children with primary of past Epstein-Barr virus infections. Virol. J. 2013; 10: 55-62.

[13] Dunmire SK, Verghese PS, Balfour HHJr. Primary Epstein-Barr virus infection. J. Clin. Virol. 2018; 102: 84-92.

[14] Puhakka L, Sarvikivi E, Lappalainen M, Surcel HM, Saxen H. Decrease in seroprevalence for herpesviruses among pregnant women in Finland: cross-sectional study of three time points 1992, 2002 and2012. Infect. Dis. (Lond.). 2016; 48(5): 406-10.

[15] Linton MS, Kroeker K, Fedorak D, Dieleman L, Fedorak RN. Prevalence of Epstein-Barr Virus in a population of patients with inflammatory bowel disease: a prospective cohort study. Aliment. Pharmacol. Ther. 2013; 38(10): 1248-54.

[16] Van Zyl DG, Mautner J, Delecluse HJ. Progress in EBV Vaccines. Front. Oncol. 2019; 9: 104.

[17] Dowd JB, Palermo T, Brite J, et al. Seroprevalence of Epstein-Barr virus infection in U.S. children ages 6-19, 20032010. PLoS One. 2013; 8(5): e 64921.

[18] Balfour HH, Sifakis F, Sliman JA, Knight JA, Schmeling DO, Thomas W. Age-Specific Prevalence of Epstein-Barr Virus Infection Among Individuals Ages 6-19 Years in the United States and Factors Affecting Its Acquisition. J. Infect. Dis. 2013; 208(8): 1286-93.

[19] Pourahamad M, Hooshmand F, Nezhad SO, Sepidkar A. EBV seroepidemiology in married and unmarried women and men in Iran. Rep. Biochem. Mol. Biol. 2014; 2(2): 94-7. 